\title{
An ISM approach for analyzing the factors in technology transfer
}

\author{
Mohammad Mahdavi Mazdeha, Mohammad Ali Shafia $^{a}$, Reza Bandarian ${ }^{\mathrm{b}}$ and Abdolmajid Kahrizia ${ }^{*}$
}

${ }^{a}$ School of Industrial Engineering, Iran University of Science and Technology, Tehran, Iran

${ }^{b}$ Research Institute of Petroleum Industry, Tehran, Iran

\section{H R O N I C L E}

\section{Article history:}

Received December 10, 2014

Received in revised format:

March 2, 2015

Accepted April 20, 2015

Available online

April 222015

Keywords:

Inter-Organizational Knowledge

Transfer

Technology Transfer

Research and Technology

Organizations

Interpretive Structural Modeling (ISM)

\begin{abstract}
A B S T R A C T
Technology transfer, from research and technology organizations (RTOs) toward local industries, is considered as one of important and significant strategies for countries' industrial development. In addition to recover the enormous costs of research and development for RTOs, successful technology transfer from RTOs toward local firms forms technological foundations and develops the ability to enhance the competitiveness of firms. Better understanding of factors influencing process of technology transfer helps RTOs and local firms prioritize and manage their resources in an effective and efficient way to maximize the success of technology transfer. This paper aims to identify important effective factors in technology transfer from Iranian RTOs and provides a comprehensive model, which indicate the interactions of these factors. In this regard, first, research background is reviewed and Cummings and Teng's model (2003) [Cummings, J. L., \& Teng, B.-S. (2003). Transferring R\&D knowledge: The key factors affecting knowledge transfer success. Journal of Engineering and Technology Management, 20(1-2), 39-68.] was selected as the basic model in this study and it was modified through suggesting new factors identified from literature of inter-organizational knowledge and technology transfer and finally a Delphi method was applied for validation of modified model. Then, research conducted used Interpretive Structural Modeling (ISM) to evaluate the relationship between the factors of final proposed model. Results indicate that there were twelve factors influencing on technology transfer process from Iranian RTOs to local firms and also the intensity of absorption capability in transferee could influence on the intensity of desorption capability in transferor.
\end{abstract}

\section{Introduction}

In the era of knowledge-based economy, acquiring new technology becomes crucial to enhance firm's competitive advantage (Lai, 2011; Lin et al., 2002). To acquire new technologies, a firm can do inhouse Research and Development (R\&D) or transferring technologies from external sources (Lai \& Tsai, 2009). Even the companies with extensive financial and technological capability may not build independent R\&D activities readily. Therefore, the ability to exploit external knowledge appears to be

* Corresponding author.

E-mail address: majid_kahrizi@ind.iust.ac.ir (A. Kahrizi) 
essential for firms' survival, especially for Small and Medium Enterprises (SMEs), which are faced with limited resources and internal capabilities (Lin et al., 2002; Morrissey \& Sergio, 2005). Firms' utilization of external sources of necessary skills through technology transfer process, more precisely from Research and Technology Organizations (RTOs), has grown rapidly since late 1980s (Barge-Gil \& Modrego, 2011). RTOs as a category of non-corporate R\&D organizations have been set up to extensively promote the creation of necessary knowledge and its utilization in determined science and technology areas (Nath \& Mrinalini, 2000). Therefore, RTOs are considered as important and useful components of the national innovation system (Leitner, 2005). These firms have different outputs ranging from basic research to product development or technical services and engineering (AlborsGarrigos et al., 2010). Technology transfer from RTOs to local firms may lead to enhance the competitiveness of national economic sectors. In addition, RTOs through effective commercialization of technological achievements produce new sources of incomes for their activities and represent their relevance to social and economic development (Sharif \& Baark, 2011).

According to several definitions of technology, knowledge has been highlighted as the core concept (e.g. Galbraith, 1967; Frey, 1989; Bohn, 1994; Khalil, 2000; Al-Mabrouk \& Soar, 2009; Lee et al., 2010). Knowledge transfer should happen in successful technology transfer process, hence knowledge transfer has been considered in many technology transfer definitions (e.g. Winebrake, 1992; Bozeman, 2000; Wahab et al., 2012; Lee et al., 2012).

Identification of factors that influence technology transfer process in various levels of intra and interorganization, as well as international technology transfer has been an open research. Since knowledge/technology transfer from RTOs to local firms is a type of inter-organization transfer, therefor the present paper focused on this area in the literature.

Creighton et al. (1985) expressed nine elements that affect technology transfer including characteristics of both formal and informal organizations, nature of the project, documentation of information, distribution of information, linker between the source of knowledge and the recipient of knowledge, capacity to transfer or receive, credibility of parties or organizations in the transaction, willingness to transmit or receive, and reward. Ounjian and Carne (1987) categorized factors, which facilitate and inhibit the technology transfer process by nature of the technology to be transferred, characteristics of the receiving organization, characteristics of the giving organization, and nature of the communications between the organizations. Gibson and Smilor (1991) determined four important variables for technology transfer processes within and between organizations. These variables are communication interactivity, geographical and cultural distance, technological equivocality, and personal motivation. Bozeman (2000) employed a “Contingent Effectiveness Model of Technology Transfer” to organize the literature on domestic technology transfer from universities and government laboratories. Bozeman's model (2000) includes five broad dimensions determine effectiveness: characteristics of the transfer agent, characteristics of the transfer media, characteristics of the transfer object, the demand environment, and characteristics of the transfer recipient. According to Stock and Tatikonda (2000), there are several variables, which influence the technology transfer process and could be synthesized into two overall sub-dimensions: a) technology uncertainty and b) organizational interaction. Technology uncertainty consists of three macro-factors: technology novelty, technology complexity and technology implicitness. Communication, coordination, and cooperation are three essential macrofactors that constitute of organizational interaction. Cummings and Teng (2003) studied of R\&D knowledge transfer within more than fifteen industries and presented a model of transfer success that includes nine key factors influencing knowledge transfer across four broad contextual domains, including: knowledge context, relational context, recipient context, and activity context. Knowledge context, contained of transferred knowledge's embeddedness and articulability. Organizational distance, physical distance, knowledge distance and norm distance are the variables that define the relational context of the transfer. Moreover, there are also factors associated with recipient context, which can influence on transfer success. These factors are project priority and learning culture. Finally, 
the fourth context in the Cummings and Teng's model (2003) is the 'activity context' that including transfer mechanisms.

Smith et al. (2008) suggested a theoretical framework, which consists of four sets of factors influencing inter-organizational knowledge transfer: resources and capabilities of both donor and recipient firms, the nature of knowledge that is being exchanged, and inter-organizational dynamics. Absorptive capacity and intra-organizational transfer capability are two key factors in both donor and recipient. In addition, transferee has to be motivated to receive knowledge and transferor must have motivation to teach. Tacitness, ambiguity and complexity are constitutive the nature of knowledge. Interorganizational knowledge transfer includes, at least, two organizations, therefore understanding the interactive dynamics among these organizations is critical. The four factors that represent interorganizational dynamics, consist of; power relations, trust and risk, social ties, and structures and mechanisms. Sung (2009) selected twelve variables from extensive literature review adopted as factors impacting on technology transfer. These factors are communication channels, management support, incentives for technology transfer, sense of common purpose, understanding the nature of business, awareness of technology transfer, collaboration among participants, government support, attitude and values, concreteness of technology, demand pull technology, and product champion.

The literature review noted that most studies in the field of technology transfer have attempted to identify important factors in technology transfer process but understanding the interaction between these factors plays essential role in making effective and efficient decisions by transferor and transferee. Hence, in these papers interactions between these factors are analyzed to provide comprehensive model that includes the factors affecting the transfer of technology from Iranian RTOs (transferor) to local firms (transferee). The remainder of this paper is organized as follows. In next section, research methods and design will be introduced and primary/modified model illustrated. In section 3, data analysis and results will be provided and finally in section 4 , research conclusions and main findings will be represented.

\section{Research Methodology}

This study is a descriptive qualitative empirical research, which applies two major methodologies included of: 1) expert panel views in a Delphi method for suggesting and validating the provided conceptual model, and 2) Interpretive Structural Modeling (ISM) is used to obtain structural relationship among the factors of final proposed model. For this purpose, literature of interorganizational knowledge and technology transfer are reviewed deeply (Section 2). Then based on selected knowledge/technology transfer model, a conceptual model is presented by considering new factors. A Delphi method applying some interview sessions in three round with related experts is used in order to analyze and modify the model. Also, an empirical research is performed using ISM in order to evaluate the relationship between the factors of final proposed model. For that, eight Iranian technology transfer experts are consulted: four from pioneer RTOs in Iran and four from academia.

\subsection{Delphi Method}

The Delphi method is an iterative process used to collect and distill the judgments of experts using a series of questionnaires interspersed with feedback (Skulmoski et al., 2007). In its original form, the Delphi method is a long-range forecasting technique that elicits, refines, and draws on the collective opinion and expertise of a panel of experts (Gupta \& Clarke, 1996). On a practical level, the Delphi method is an alternative to formal meetings, interviews, or other face-to-face interactions. Unlike meetings, the Delphi method allows all participants to have equal opportunity to be involved with the decision-making process (Geist, 2010). In most cases, a Delphi method consisted of four planning and execution activities (Loo, 2002):

- Problem Definition

- Panel Selection 
- Determining Panel Size

- Conducting the Delphi Rounds

According to Loo (2002) problem definition is an important step in Delphi method to ensure nature, scope, investigating issues and expected outcomes. Policing knowledge, personal experiences and being stakeholders are considered as essential factors for panel selection. Also stability in panel membership is very important in panel selection because of roundly conduction of this method. Panel selection might not be random. There is no sample size advocated for Delphi studies and for those from strong qualitative background, less than 15-30 could be appropriate. A Delphi study usually involves three or five rounds.

\subsubsection{Primary Model}

Technology transfer body of research and models in this area reviewed exactly and Cumming and Teng's model (2003) selected as the basic model according to comprehension, high usability capability and applicability. The main reasons for this choice can be stated as follows;

- This model is based on a comprehensive study about inter-organizational R\&D knowledge transfer in 15 industries;

- Enlisting from technology transfer, innovation and strategic management beside interorganizational knowledge transfer in modeling;

- An executive approach to knowledge and technology transfer contexts and appropriate clustering of effective components and factors.

Cummings and Teng's model (2003) consisted of four contexts and nine factors (Fig. 1) which would be explained below:

Knowledge context

Relational context

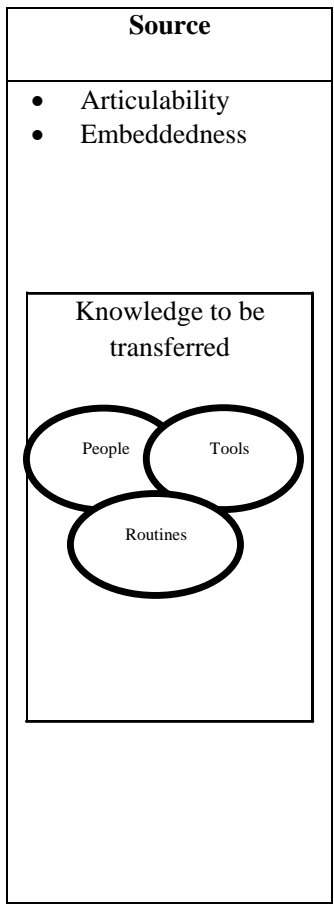

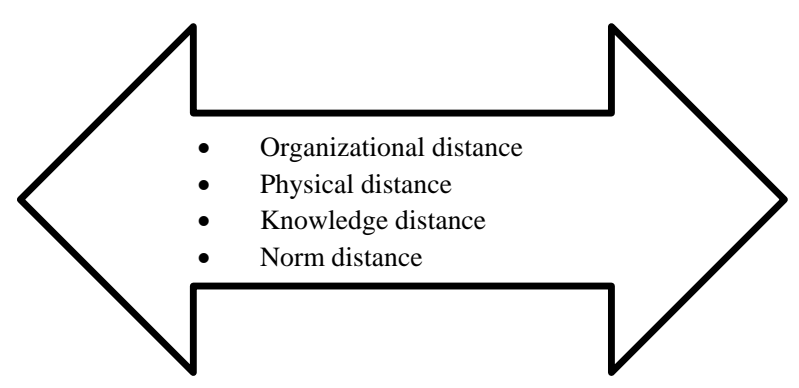

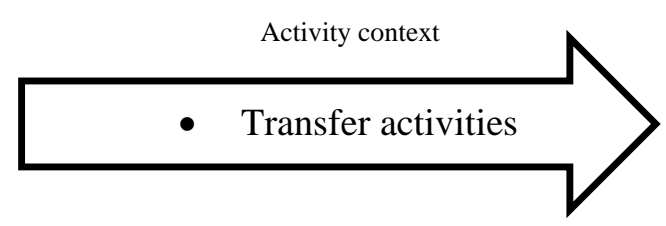

Fig. 1. Cummings \& Teng's model (2003)
Recipient context

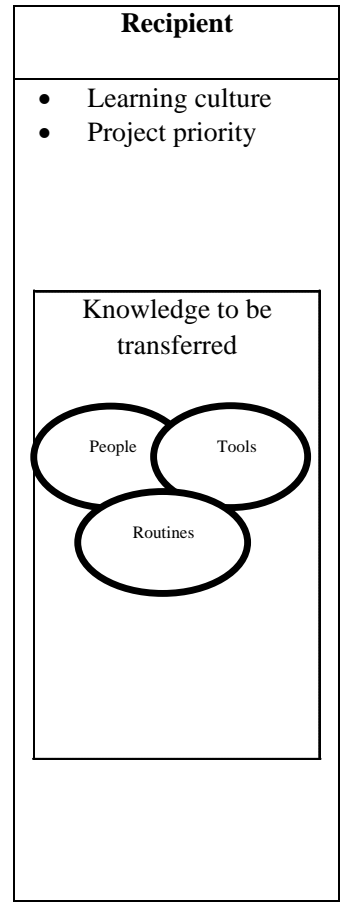

\section{Knowledge Context}

The "knowledge context" includes the transferred knowledge's embeddedness and articulability. According to Cummings and Teng (2003), the basic argument in knowledge context is that knowledge transfer success requires both mentioned parties of transfer to develop an understanding of where the 
desired knowledge resides within the source, and that they both participate in the processes by which the knowledge is made accessible. Lacking an understanding of where the knowledge resides within the source, the recipient may omit collection of a key knowledge component. Moreover, both transferor and transferee involvement in the articulation process is important because it (a) supports the recipient's later ownership of and commitment to the knowledge, (b) provides a bridge between less organizationally internalized parties, and (c) enhances the relationship (reduces any relationship distance) between the parties. Knowledge embeddedness is the amount of knowledge elements and related sub-networks will be needed to be transferred, absorbed, adapted and adopted by the recipient. Knowledge can be embedded in people, tools, and routines, as well as in related sub-networks among these elements (see Fig. 1). Knowledge articulability represents the extent to which knowledge can be verbalized, written, drawn or otherwise articulated.

\section{Relational Context}

Cummings and Teng (2003) stated four variables that define the relational context of the transfer. These factors are:

- Organizational distance is based on the organizing mode of the source and recipient of technology,

- Physical distance refers to the difficulty, time requirement, and expense of communicating and face-to-face getting together,

- Knowledge distance is the degree to which the source and recipient possess similar knowledge,

- Norm distance is the degree of organizational culture and value systems sameness of knowledge transfer parties.

\section{Recipient Context}

In addition to the knowledge and relational factors, there are also factors associated with the recipient's receptiveness for learning new knowledge/technology and to the extent of effort put forward to undertake transfer activities, which influence on transfer success. Based on Cummings and Teng's view, these factors are the priority of the project for the recipient and its predisposition for learning that included in the "recipient context". Since projects with different priorities may receive different degrees of attention and/or resources, project priority was included as a recipient-context variable. Learning culture represents the extensive set of routines and learning competencies designed to retain and nurture transferred knowledge may achieved by recipient

\section{Activity Context}

The fourth context in the Cummings and Teng's model (2003) is the "activity context”. The knowledge transfer literature identifies three interdependent types of knowledge transfer activities, including those focused on assessing the form and embeddedness of the knowledge; those focused on establishing and managing an administrative structure through, which differences and issues between the parties can be accommodated and reduced, and those focused on transferring the knowledge.

\subsubsection{Modified Model}

Four important factors noted in literature were added to selected model in order to model modification (Fig. 2). These factors could be describe as below:

Factors added in Knowledge Context:

- Complexity of Technology: Interdependence of technology components, the level of interdependence between foreign substances and its related technology and the ease of use of technology (Stock \& Tatikonda, 2000; Lin \& Berg, 2001). 
- Source Motivation to Teach: Effort of technology source (transferor) to provide appropriate documents and submit appropriate training in relation to the transfer of technology to the recipient and the sender's willingness to exchange and movement of personnel in order to better transfer (Ounjian \& Carne, 1987).

A factor added in Relational Context:

- Mutual Trust: Technology provider's willing to share information and knowledge with recipient and also recipient confidence on shared knowledge value (Lane et al., 2001).

A factor added in Recipient Context:

- Absorptive Capacity: The ability of the receiver to detect and recognize the value of new technology, absorbing the technology and using it for commercial purposes (Cohen \& Levinthal, 1990).

Knowledge context

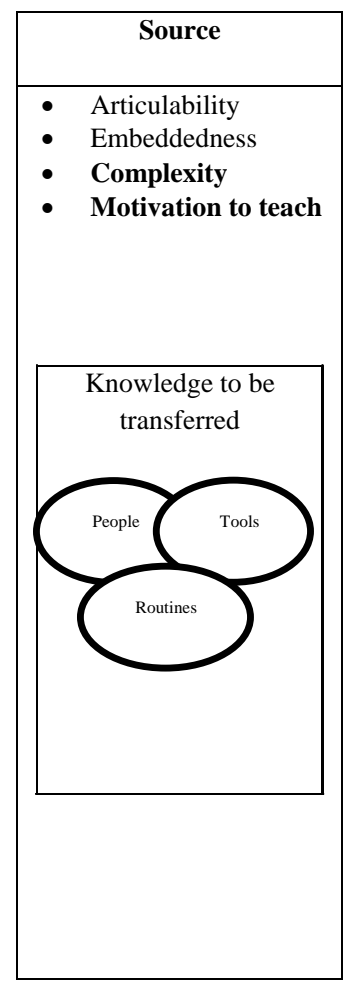

Relational context

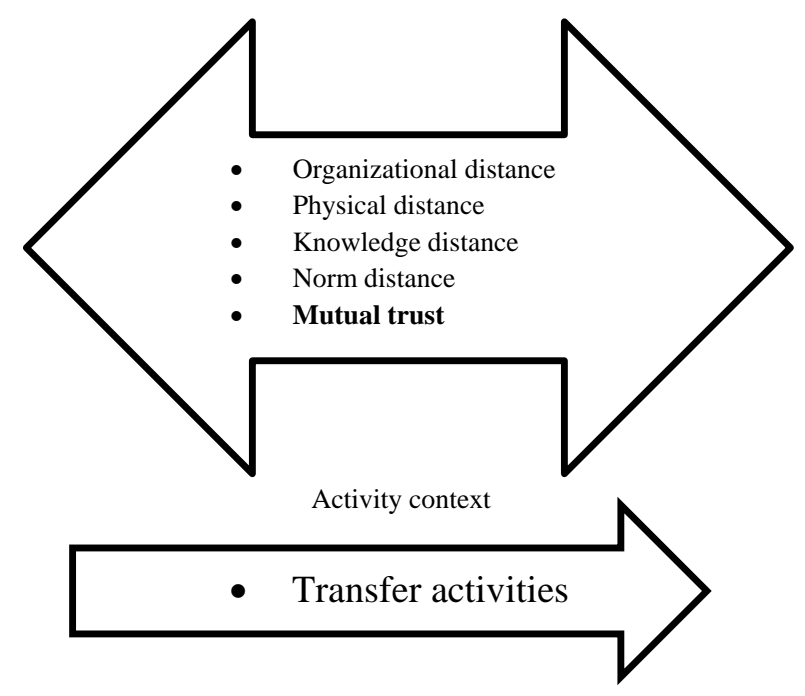

Fig. 2. The modified proposed model
Recipient context

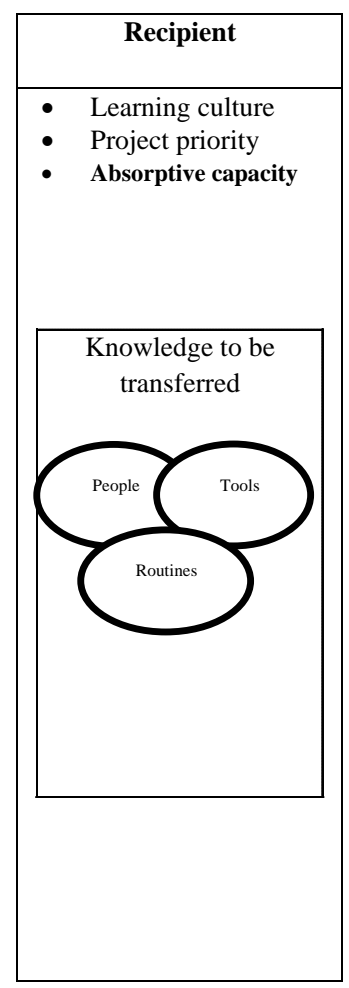

It should be noted that added factors were noticed in many former studies shown in Table 1.

Table 1

Added factors based on literature review

\begin{tabular}{ll}
\hline Added Factor & Researchers Noticed to \\
\hline Complexity of Technology & $\begin{array}{l}\text { (Kogut \& Zander, 1993), (Simonin, 1999), (Stock \& Tatikonda, 2000), (Lin \& } \\
\text { Berg, 2001) }\end{array}$ \\
$\begin{array}{l}\text { Source Motivation } \\
\text { to Teach }\end{array}$ & $\begin{array}{l}\text { 2008) } \\
\text { Mutual Trust }\end{array}$ \\
(Inkpen, 2000), (Lane et al., 2001), (Lin et al, 2005), (Smith et al., 2008)
\end{tabular}




\subsection{ISM Method}

Warfield (1974) is believed to be the first who developed theoretical development of ISM and the objective of understanding the complex relationships among elements was presented by Borade and Bansod (2012). Farris and Sage (1975); Sage and Smith (1977); Sage (1977) contributed to the development and application of the ISM methodology for a variety of purposes - especially those concerned with decision analysis/ making (Jadhav et al., 2014). According to Bouzon et al. (2015), the main notion of ISM is to use experts' experience and knowledge to frame a complicated system into several sub-systems and construct a multilevel structural model. Interpretive Structural Modeling (ISM) (Singha \& Kant, 2008):

- is interpretive as the judgment of the group decides whether and how the variables are related;

- is structural as on the basis of relationship, an overall structure is extracted from the complex set of variables;

- is a modeling technique as the specific relationships and overall structure are portrayed in a graphical model.

Generally, ISM approach is a combination of three modeling languages-words, digraphs, and discrete mathematics- that used for an effective decision making process (Jia et al., 2014). Various steps involved in ISM approach are illustrated in Fig. 3.

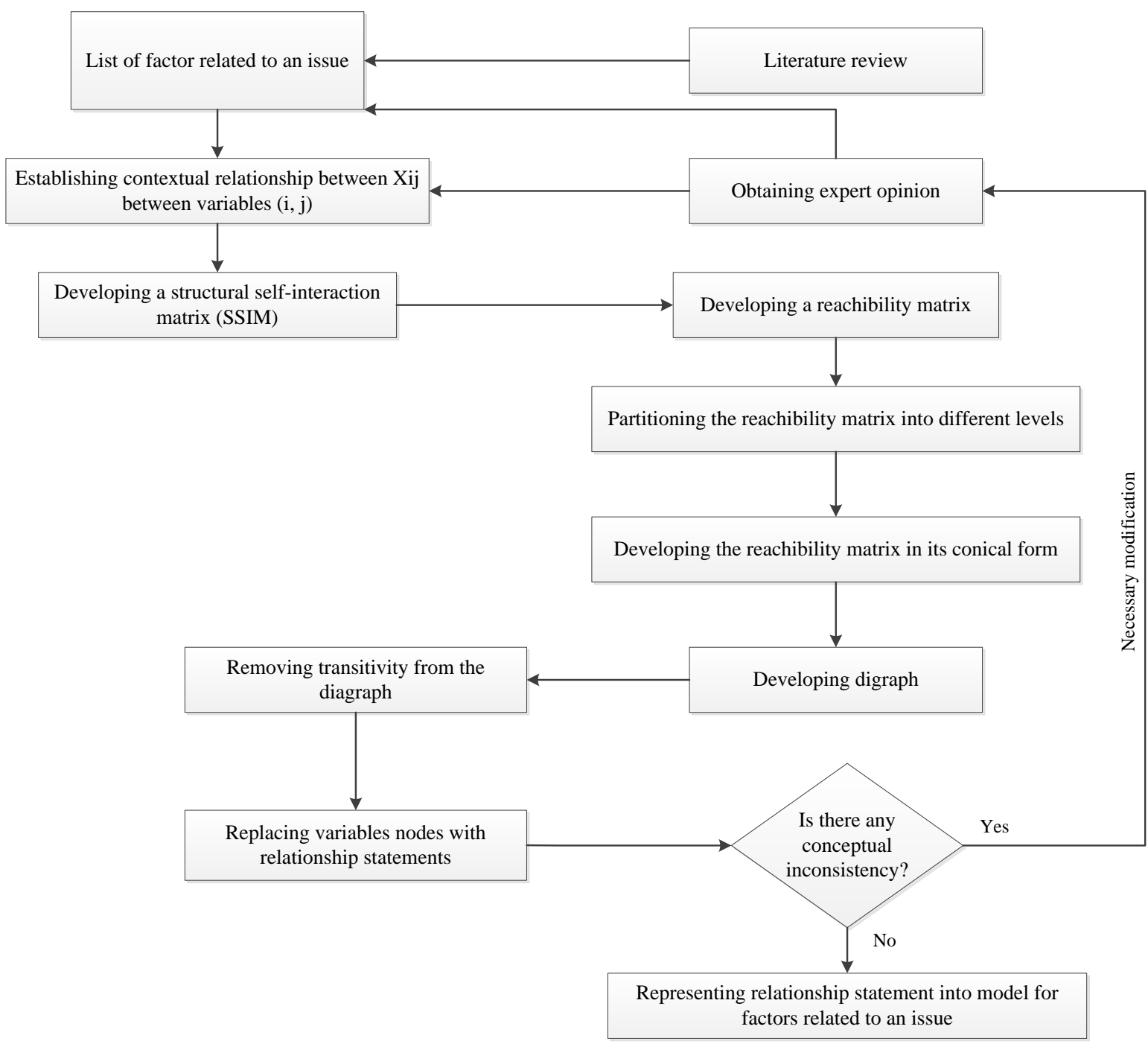

Fig. 3. Flow diagram for preparing ISM model (Kannan et al., 2009) 


\section{Results and Discussion}

Data analysis based on Delphi and ISM methods proposed in this section. A nine scale Likert based questionnaire and interview sessions has been conducted in three rounds with eight selected academics and also well-known experienced executive experts in Delphi method and another verified questionnaire has been applied for collecting and comparing three technology transfer projects. Delphi results have been shown in Table 2. In the third round, the results of the second round of respected experts are summarized and presented. Experts respected the importance of thirteen factors adjustment of the model that were expressed in the second round. So Delphi method completed in third round. Delphi data analysis indicated that experts agreed strongly with twelve of the thirteen factors in proposed model and only "Physical Distance" could be eliminated based on experts' views. Delphi method results also confirmed Cummings and Teng (2003) studies in this point that "Physical Distance" would not have considerable effects in R\&D knowledge and technology transfer. Therefor, this factor has been ignored in the final proposed model. Although Cummings and Teng (2003) did not note the "Organizational Distance" as an important and effective factor in in R\&D knowledge and technology transfer, experts' views in Delphi method have indicated the importance of this factor based on Iranian firms situations. Hence “Organizational Distance” has been considered in final proposed model.

Table 2

Delphi results

\begin{tabular}{|c|c|c|c|c|c|}
\hline \multirow[b]{2}{*}{ No } & \multirow[b]{2}{*}{ Factor } & \multicolumn{2}{|c|}{ First Round } & \multicolumn{2}{|c|}{ Second Round } \\
\hline & & $\begin{array}{l}\text { Expert who noted } \\
\text { factor importance } \\
\text { greater than mean } \\
(>5)\end{array}$ & $\begin{array}{c}\text { Expert who noted } \\
\text { factor importance } \\
\text { lower than or equal } \\
\text { mean }(\leq 5)\end{array}$ & $\begin{array}{l}\text { Expert who noted } \\
\text { factor importance } \\
\text { greater than mean } \\
\qquad(>5)\end{array}$ & $\begin{array}{c}\text { Expert who noted } \\
\text { factor importance } \\
\text { lower than or equal } \\
\text { mean }(\leq 5)\end{array}$ \\
\hline 1 & Knowledge Embeddedness & 8 & & 8 & \\
\hline 2 & Knowledge Articulability & 8 & & 8 & \\
\hline 3 & Complexity of Technology & 8 & & 8 & \\
\hline 4 & Motivation to Teach & 6 & 2 & 6 & 2 \\
\hline 5 & Organizational Distance & 6 & 2 & 6 & 2 \\
\hline 6 & Physical Distance & 3 & 5 & 1 & 7 \\
\hline 7 & Knowledge Distance & 8 & & 8 & \\
\hline 8 & Norm Distance & 6 & 2 & 6 & 2 \\
\hline 9 & Mutual Trust & 8 & & 8 & \\
\hline 10 & Project Priority & 7 & 1 & 7 & 1 \\
\hline 11 & Learning Culture & 8 & & 8 & \\
\hline 12 & Absorptive Capacity & 8 & & 8 & \\
\hline 13 & Transfer Mechanisms & 8 & & 8 & \\
\hline
\end{tabular}

After obtaining the final model, ISM technique was applied in order to explain the interaction of these factors. The main steps, which lead to the development of ISM model, are illustrated below.

Step 1: Data gathering and formation of structural self-interaction matrix (SSIM):

As noted before, final model included of 12 factors was obtained based on literature review and expert opinion (Table 3).

\section{Table 3}

Factors of final proposed model

\begin{tabular}{lclc}
\hline Factors & Abbreviation & Factors & Abbreviation \\
\hline Knowledge Embeddedness & KE & Norm Distance & ND \\
Knowledge Articulability & KA & Mutual Trust & MT \\
Complexity of Technology & CT & Project Priority & PP \\
Motivation to Teach & MoT & Learning Culture & LC \\
Organizational Distance & OD & Absorptive Capacity & AC \\
Knowledge Distance & KD & Transfer Mechanisms & TM \\
\hline
\end{tabular}


The following four symbols have been used for developing SSIM to denote the direction of relationship between two factors $\mathrm{i}$ and $\mathrm{j}$ :

$\mathrm{V}$-factor ' $\mathrm{i}$ ' has an effect on factor ' $\mathrm{j}$ ';

A-factor ' $\mathrm{j}$ ' has an effect on factor ' $\mathrm{i}$ ';

$\mathrm{X}$-factor ' $\mathrm{i}$ ' has a reciprocal effect on factor ' $\mathrm{j}$ ';

$\mathrm{O}$ - factor ' $\mathrm{i}$ ' has no effect on factor ' $\mathrm{j}$ ' and vice versa.

Based on this contextual relationship, a SSIM has developed as per the opinion of experts. The final relationship is shown in Table 4.

Table 4

Structural Self-Interaction Matrix (SSIM)

\begin{tabular}{|c|c|c|c|c|c|c|c|c|c|c|c|c|c|}
\hline $\begin{array}{c}\text { Factor } \\
\text { No. }\end{array}$ & Factors & $\begin{array}{c}12 \\
\text { TM }\end{array}$ & $\begin{array}{l}11 \\
\mathrm{AC}\end{array}$ & $\begin{array}{l}\mathbf{1 0} \\
\mathrm{LC}\end{array}$ & $\begin{array}{c}\mathbf{9} \\
\text { PP }\end{array}$ & $\begin{array}{c}\mathbf{8} \\
\text { MT }\end{array}$ & $\begin{array}{c}7 \\
\text { ND } \\
\end{array}$ & $\begin{array}{c}\mathbf{6} \\
\mathrm{KD} \\
\end{array}$ & $\begin{array}{c}5 \\
\text { OD } \\
\end{array}$ & $\begin{array}{c}4 \\
\mathrm{MoT} \\
\end{array}$ & $\begin{array}{c}3 \\
\mathrm{CT} \\
\end{array}$ & $\begin{array}{c}\mathbf{2} \\
\mathrm{KA} \\
\end{array}$ & $\begin{array}{c}1 \\
\mathrm{KE}\end{array}$ \\
\hline 1 & KE & V & $\mathrm{O}$ & $\mathrm{O}$ & $\mathrm{O}$ & $\mathrm{O}$ & $\mathrm{O}$ & V & $\mathrm{O}$ & V & $X$ & $\mathrm{X}$ & \\
\hline 2 & KA & V & $\mathrm{X}$ & $\mathrm{O}$ & $\mathrm{O}$ & $\mathrm{O}$ & $\mathrm{O}$ & $\mathrm{X}$ & $\mathrm{O}$ & V & $X$ & & \\
\hline 3 & CT & V & $\mathrm{O}$ & $\mathrm{O}$ & V & $\mathrm{O}$ & $\mathrm{O}$ & V & $\mathrm{O}$ & V & & & \\
\hline 4 & MoT & $X$ & $\mathrm{X}$ & $\mathrm{X}$ & $\mathrm{V}$ & $\mathrm{X}$ & $\mathrm{V}$ & $\mathrm{X}$ & $\mathrm{O}$ & & & & \\
\hline 5 & OD & V & $\mathrm{O}$ & $\mathrm{O}$ & $\mathrm{O}$ & $\mathrm{O}$ & V & $\mathrm{O}$ & & & & & \\
\hline 6 & KD & $\mathrm{X}$ & A & A & $\mathrm{O}$ & $\mathrm{V}$ & $\mathrm{O}$ & & & & & & \\
\hline 7 & ND & $\mathrm{X}$ & $\mathrm{O}$ & $\mathrm{O}$ & $\mathrm{O}$ & $\mathrm{V}$ & & & & & & & \\
\hline 8 & MT & $\mathrm{X}$ & O & V & $\mathrm{V}$ & & & & & & & & \\
\hline 9 & PP & V & $\mathrm{O}$ & $\mathrm{O}$ & & & & & & & & & \\
\hline 10 & LC & V & $\mathrm{X}$ & & & & & & & & & & \\
\hline 11 & AC & $\mathrm{X}$ & & & & & & & & & & & \\
\hline 12 & TM & & & & & & & & & & & & \\
\hline
\end{tabular}

Step 2: Reachability matrix

The next step in ISM approach is to develop an initial reachability matrix from SSIM. For this, SSIM is converted into the initial reachability matrix by substituting the four symbols (i.e., V, A, X or O) of SSIM by $1 \mathrm{~s}$ or $0 \mathrm{~s}$ in the initial reachability matrix. The rules for this substitution are as follows:

(i) If $\mathrm{X}_{\mathrm{i}, \mathrm{j}}$ entry in SSIM is $\mathrm{V}$, then $\mathrm{X}_{\mathrm{i}, \mathrm{j}}$ is set to 1 , and $\mathrm{X}_{\mathrm{j}, \mathrm{i}}$ is set as 0 ;

(ii) If $X_{i, j}$ entry in SSIM is $A$, then $X_{i, j}$ is set to 0 , and $X_{j, i}$ is set as 1 ;

(iii) If $\mathrm{X}_{\mathrm{i}, \mathrm{j}}$ entry in SSIM is $\mathrm{X}$, both $\mathrm{X}_{\mathrm{i}, \mathrm{j}}$ and $\mathrm{X}_{\mathrm{j}, \mathrm{i}}$ is set as 1 ;

(iv) If $\mathrm{X}_{\mathrm{i}, \mathrm{j}}$ entry in SSIM is $\mathrm{O}$, both $\mathrm{X}_{\mathrm{i}, \mathrm{j}}$ and $\mathrm{X}_{\mathrm{j}, \mathrm{i}}$ is set as 0 .

Following these rules, the initial reachability matrix is prepared (Table 5). Then, the initial reachability matrix is checked for transitivity. The transitivity of the contextual relationships is a basic assumption made in ISM and it states that if variable $\mathrm{X}$ is related to variable $\mathrm{Y}$ and variable $\mathrm{Y}$ is related to variable $\mathrm{Z}$, then variable $\mathrm{X}$ is necessarily related to variable $\mathrm{Z}$. After incorporating the transitivity concept as described above, the final reachability matrix is obtained (Table 6).

\section{Table 5}

The initial reachability matrix

\begin{tabular}{cllllllllllll}
\hline Factors & KE & KA & CT & MoT & OD & KD & ND & MT & PP & LC & AC & TM \\
\hline KE & 1 & 1 & 1 & 1 & 0 & 1 & 0 & 0 & 0 & 0 & 0 & 1 \\
\hline KA & 1 & 1 & 1 & 1 & 0 & 1 & 0 & 0 & 0 & 0 & 1 & 1 \\
\hline CT & 1 & 1 & 1 & 1 & 0 & 1 & 0 & 0 & 1 & 0 & 0 & 1 \\
\hline MoT & 0 & 0 & 0 & 1 & 0 & 1 & 1 & 1 & 1 & 1 & 1 & 1 \\
\hline OD & 0 & 0 & 0 & 0 & 1 & 0 & 1 & 0 & 1 & 0 & 0 & 1 \\
\hline KD & 0 & 1 & 0 & 1 & 0 & 1 & 0 & 1 & 0 & 0 & 0 & 1 \\
\hline ND & 0 & 0 & 0 & 0 & 0 & 0 & 1 & 1 & 0 & 0 & 0 & 1 \\
\hline MT & 0 & 0 & 0 & 1 & 0 & 0 & 0 & 1 & 1 & 1 & 0 & 1 \\
\hline PP & 0 & 0 & 0 & 0 & 0 & 0 & 0 & 0 & 1 & 0 & 0 & 1 \\
\hline LC & 0 & 0 & 0 & 1 & 0 & 1 & 0 & 0 & 0 & 1 & 1 & 1 \\
\hline AC & 0 & 1 & 0 & 1 & 0 & 1 & 0 & 0 & 0 & 1 & 1 & 1 \\
\hline TM & 0 & 0 & 0 & 0 & 0 & 1 & 1 & 1 & 0 & 0 & 1 & 1 \\
\hline
\end{tabular}


Also, the final reachability matrix (Table 6) indicates each factor's driving power and dependence power. The driving power of a factor is the total number of factors that can be alleviated by it. The dependence power of a factor is the total number of factors that can possibly alleviate it. The drive power of a factor is derived by summing up the number of ones in the rows and its dependence power by summing up the number of ones in the column.

Table 6

The final reachability matrix

\begin{tabular}{|c|c|c|c|c|c|c|c|c|c|c|c|c|c|}
\hline Factors & $\mathrm{KE}$ & KA & CT & MoT & OD & KD & ND & MT & PP & $\mathrm{LC}$ & AC & TM & $\begin{array}{c}\text { Driving } \\
\text { Power }\end{array}$ \\
\hline $\mathrm{KE}$ & 1 & 1 & 1 & 1 & 0 & 1 & $1^{*}$ & $1^{*}$ & $1^{*}$ & $1^{*}$ & $1^{*}$ & 1 & 11 \\
\hline KA & 1 & 1 & 1 & 1 & 0 & 1 & $1^{*}$ & $1^{*}$ & $1^{*}$ & $1^{*}$ & 1 & 1 & 11 \\
\hline CT & 1 & 1 & 1 & 1 & 0 & 1 & $1^{*}$ & $1^{*}$ & 1 & $1^{*}$ & $1^{*}$ & 1 & 11 \\
\hline MoT & 0 & $1^{*}$ & 0 & 1 & 0 & 1 & 1 & 1 & 1 & 1 & 1 & 1 & 9 \\
\hline OD & 0 & 0 & 0 & $1^{*}$ & 1 & $1^{*}$ & 1 & $1^{*}$ & 1 & $1^{*}$ & $1^{*}$ & 1 & 9 \\
\hline KD & $1^{*}$ & 1 & $1^{*}$ & 1 & 0 & 1 & $1^{*}$ & 1 & $1^{*}$ & $1^{*}$ & $1^{*}$ & 1 & 11 \\
\hline ND & 0 & 0 & 0 & $1^{*}$ & 0 & $1^{*}$ & 1 & 1 & $1^{*}$ & $1^{*}$ & $1^{*}$ & 1 & 8 \\
\hline MT & 0 & $1^{*}$ & 0 & 1 & 0 & $1^{*}$ & $1^{*}$ & 1 & 1 & 1 & $1^{*}$ & 1 & 9 \\
\hline PP & 0 & 0 & 0 & 0 & 0 & $1^{*}$ & $1^{*}$ & $1^{*}$ & 1 & 0 & $1^{*}$ & 1 & 6 \\
\hline LC & 0 & $1^{*}$ & 0 & 1 & 0 & 1 & $1^{*}$ & $1^{*}$ & $1^{*}$ & 1 & 1 & 1 & 9 \\
\hline AC & $1^{*}$ & 1 & $1^{*}$ & 1 & 0 & 1 & $1^{*}$ & $1^{*}$ & $1^{*}$ & 1 & 1 & 1 & 11 \\
\hline TM & 0 & $1^{*}$ & 0 & $1^{*}$ & 0 & 1 & 1 & 1 & $1^{*}$ & $1^{*}$ & 1 & 1 & 9 \\
\hline $\begin{array}{l}\text { Dependence } \\
\text { Power }\end{array}$ & 5 & 9 & 5 & 11 & 1 & 12 & 12 & 12 & 12 & 11 & 12 & 12 & \\
\hline
\end{tabular}

* Used in matrix for "rule of transitivity".

\section{Step 3: Level partitions}

From the final reachability matrix, for each factor, reachability set and antecedent sets are derived. The reachability set consists of the factor itself and the other factor that it may impact, whereas the antecedent set consists of the factor itself and the other factor that may impact it. Thereafter, the intersection of these sets is derived for all the factors and levels of different factor are determined. The factors for which the reachability and the intersection sets are the same occupy the top level in the ISM hierarchy. The top-level factors are those factors that will not lead the other factors above their own level in the hierarchy. Once the top-level factor is identified, it is removed from consideration. Then, the same process is repeated to find out the factors in the next level. This process is continued until the level of each factor is found. The Factors, along with their reachability set, antecedent set, intersection set and the levels, are shown in Tables 7-9. The identified levels aids in building the diagram and the final model of ISM.

Table 7

Level partition-iteration 1

\begin{tabular}{ccccc}
\hline Factors & Reachability set & Antecedent set & Intersection set \\
\hline KE & $1,2,3,4,6,7,8,9,10,11,12$ & $1,2,3,6,11$ & $1,2,3,6,11$ \\
KA & $1,2,3,4,6,7,8,9,10,11,12$ & $1,2,3,4,6,8,10,11,12$ & $1,2,3,4,6,8,10,11,12$ \\
CT & $1,2,3,4,6,7,8,9,10,11,12$ & $1,2,3,6,11$ & $1,2,3,6,11$ \\
MoT & $2,4,6,7,8,9,10,11,12$ & $1,2,3,4,5,6,7,8,9,11,12$ & $2,4,6,7,8,10,11,12$ \\
OD & $4,5,6,7,8,9,10,11,12$ & 5 & 5 & Level \\
KD & $1,2,3,4,6,7,8,9,10,11,12$ & $1,2,3,4,5,6,7,8,9,10,11,12$ & $1,2,3,4,6,7,8,9,10,11,12$ & I \\
ND & $4,6,7,8,9,10,11,12$ & $1,2,3,4,5,6,7,8,9,10,11,12$ & $4,6,7,8,9,10,11,12$ \\
MT & $2,4,6,7,8,9,10,11,12$ & $1,2,3,4,5,6,7,8,9,10,11,12$ & $2,4,6,7.8,9,10,11,12$ \\
PP & $6,7,8,9,11,12$ & $1,2,3,4,5,6,7,8,9,10,11,12$ & I \\
LC & $2,4,6,7,8,9,10,9,11,12$ & I \\
AC & $1,2,3,4,6,7,8,9,10,11,12$ & $1,2,3,4,5,6,7,8,9,10,11,12$ & $1,2,3,4,6,7,8,9,10,11,12$ & I \\
TM & $2,4,6,7,8,9,10,11,12$ & $1,2,3,4,5,6,7,8,9,10,11,12$ & $2,4,6,7,8,9,10,11,12$ & I \\
\hline
\end{tabular}


Table 8

Level partition-iteration 2

\begin{tabular}{ccccc}
\hline Factors & Reachability set & Antecedent set & Intersection set & Level \\
\hline KE & $1,2,3,4,10$ & $1,2,3$ & $1,2,3$ & \\
KA & $1,2,3,4,10$ & $1,2,3,4,10$ & $1,2,3,4,10$ & II \\
CT & $1,2,3,4,10$ & $1,2,3$ & $1,2,3$ & \\
MoT & $2,4,10$ & $1,2,3,4,5,10$ & $2,4,10$ & II \\
OD & $4,5,10$ & 5 & 5 & \\
LC & $2,4,10$ & $1,2,3,4,5,10$ & $2,4,10$ & II \\
\hline
\end{tabular}

Table 9

Level partition-iteration 3

\begin{tabular}{ccccc}
\hline Factors & Reachability set & Antecedent set & Intersection set & Level \\
\hline KE & 1,3 & 1,3 & 1,3 & III \\
CT & 1,3 & 1,3 & 1,3 & III \\
OD & 5 & 5 & 5 & III \\
\hline
\end{tabular}

\section{Step 4: Formation of ISM-based model}

Based on the level partition presented in Tables 7-9, and from the final reachability matrix (Table 6), the structural model is generated by vertices and edges. Out of 12 factors, three are lying at the bottom level and six are at top level of ISM model. 'Knowledge Embeddedness', 'Complexity of Technology' and 'Organizational Distance' have lying at the bottom level of model. 'Knowledge Distance', 'Norm Distance', 'Mutual Trust', 'Project Priority', 'Absorptive Capacity' and 'Transfer Mechanisms' has lying at the top level of model. Rest three factors i.e. 'Knowledge Articulability', 'Motivation to Teach' and 'Learning Culture' are lying in between top and bottom levels. This graph is called digraph. After removing the transitivity's as described in the ISM methodology, ISM model has been made as shown in Fig. 4.

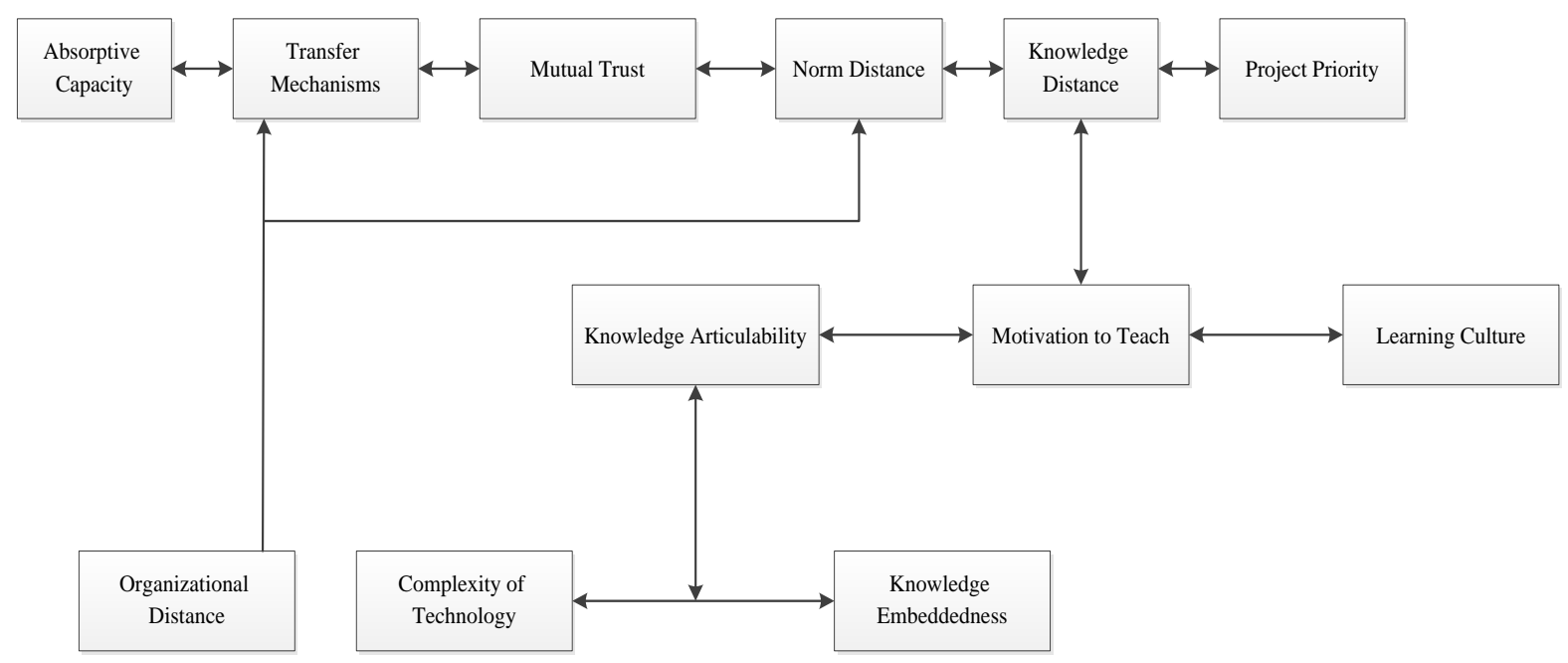

Fig. 4. ISM-based model for technology transfer from Iranian RTOs to local firms

\section{Step 5: MICMAC analysis}

The objective of the MICMAC analysis is to evaluate the driving power and the dependence power of variables. Based on their drive power and dependence power, the factors have been classified into four categories i.e. autonomous factors, linkage factors, dependent and independent factors (Fig. 5). Higher dependence and lower driver power indicate dependent factors, whereas lower dependence and higher 
driver power indicate independent factors. Lower dependence and driver power indicate autonomous factors, whereas higher dependence and driver power indicate linkage factors. It is observed that a variable with strong driving power called as the key variable falls in the category of the independent or linkage factors.

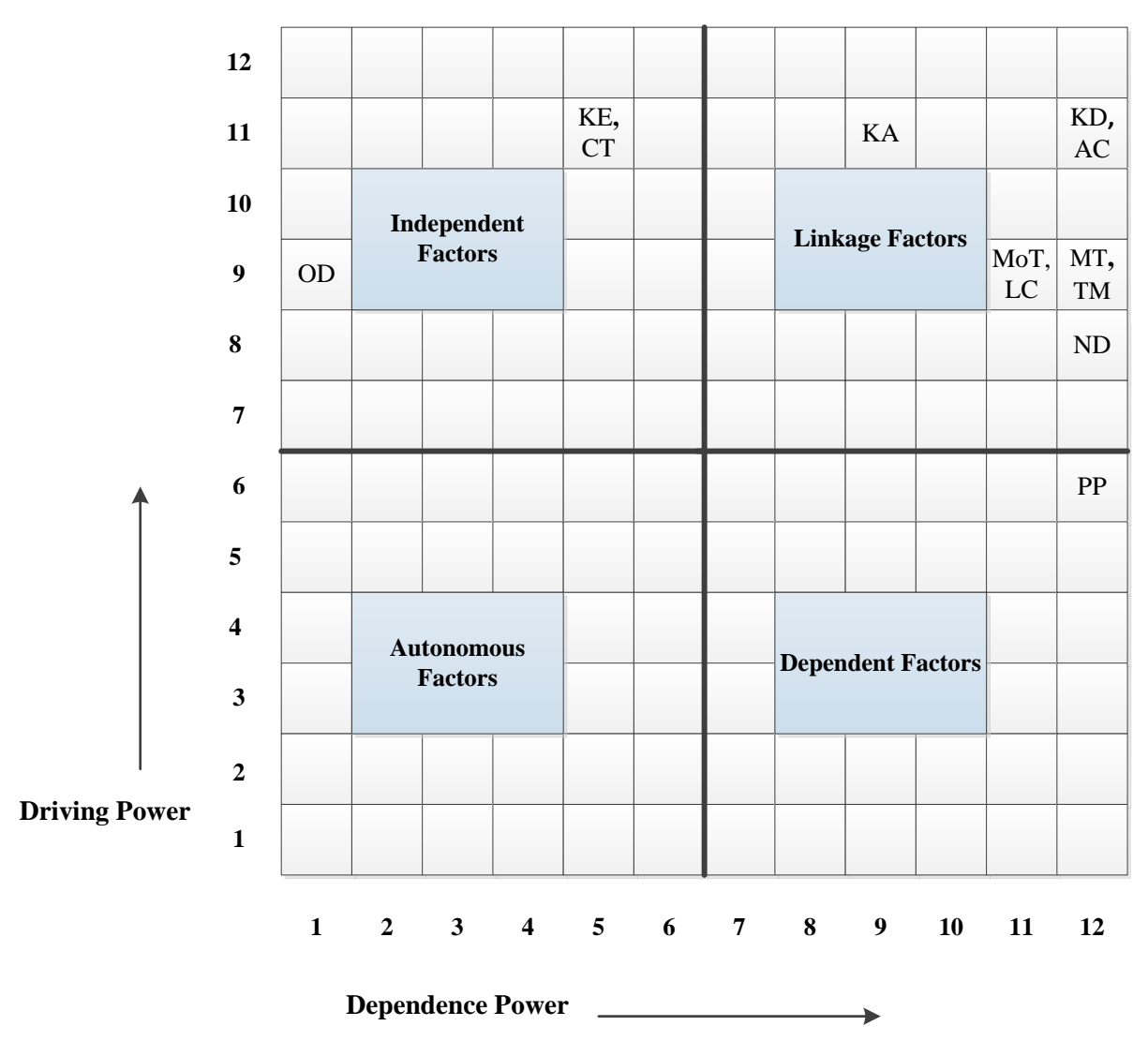

Fig. 5. Driving Power and Dependence Power Diagram

\section{Conclusion}

Literature review and experts' views has determined that the "Knowledge Embeddedness", "Knowledge Articulability", "Complexity of Technology", "Motivation to Teach from Transferor", "Organizational Distance”, "Knowledge Distance”, "Norm Distance”, "Mutual Trust”, "Project Priorities", "Learning Culture”, "Absorptive Capacity” and "Transfer Activities" are the most important factors that influence the transfer of technology from Iranian RTOs to local firms. The proposed ISMbased model for technology transfer from Iranian RTOs to local firms has indicated that absorption capacity influenced transfer activities and affected by transfer activities. If transferee maintains the acceptable level of absorption capacity and getting technology is a high priority for this party and also relationship with mutual trust between the parties formed, the interaction of these factors increases the transferor's motivation for teaching and explicitation of internal dimensions of technology. Of course, in addition, high absorption capacity and priority in transferee party, creating a trustworthy relationship between the parties and motivation of teaching in transferor is influenced by factors such as the presence of a learning culture in the transferee, knowledge distance and articulability level of knowledge embedded in technology. When the transferee is benefited from learning culture, motivation of teaching can be affected in transferor and parties set efforts in order to overcome the knowledge gap for articulating the knowledge embedded in technology. On the other hand, if the nature of transferring technology were complex and so embedded, motivation of teaching in transferor party in order to try for articulating of knowledge embedded in technology would be decreased. The complex and 
knowledge embedded technology requires an increased level of interaction between the parties to expedite the process of teaching and learning. If the teams involved in the transfer process have close norms (less normative distance) and the high level of mutual trust, despite the complexity and knowledge embeddness of technology, the transferee will be able to take advantage of its absorption capacity of the source to remove the existing knowledge gap by increasing the level of trust.

\section{References}

Albors-Garrigos, J., Zabaleta, N., \& Ganzarain, J. (2010). New R\&D management paradigms: Rethinking research and technology organizations strategies in regions. $R \& D$ Management, 40(5), 435-454.

Al-Mabrouk, K., \& Soar, J. (2009). An analysis of the major issues for successful information technology transfer in Arab countries. Journal of Enterprise Information Management, 22(5), 504522.

Barge-Gil, A., \& Modrego, A. (2011). The impact of research and technology organizations; measurement and determinants. The Journal of Technology Transfer, 36(1), 61-83.

Bohn, R. E. (1994). Measuring and managing technological knowledge. MIT Sloan Management Review, Fall, 61-73.

Borade, A. B., \& Bansod, S. V. (2012). Interpretive Structural Modeling-based Framework for VMI Adoption in Indian Industries. The International Journal of Advanced Manufacturing Technology, 58(9-12), 1227-1242.

Bouzon, M., Govindan, K., \& Rodriguez, C. M. (2015). Reducing the extraction of minerals: Reverse logistics in the machinery manufacturing industry sector in Brazil using ISM approach. Resources Policy (In Press).

Bozeman, B. (2000). Technology transfer and public policy: A review of research and theory. Research Policy, 29(4-5), 627-655.

Creighton, J. W., Jolly, J. A., \& Buckles, T. A. (1985). The manager's role in technology transfer. The Journal of Technology Transfer, 10(1), 65-81.

Cummings, J. L., \& Teng, B.-S. (2003). Transferring R\&D knowledge: The key factors affecting knowledge transfer success. Journal of Engineering and Technology Management, 20(1-2), 39-68.

Frey, R. E. (1989). A Philosophical framework for understanding technology. Journal of Industrial Teacher Education, 27, 23-35.

Galbraith, J. K. (1967). The New Industrial State. Princeton University Press.

Geist , M. R. (2010). Using the delphi method to engage stakeholders: A comparison of two studies. Evaluation and Program Planning, 33(2), 147-154.

Gibson, D. V., \& Smilor, R. W. (1991). Key variables in technology transfer: A field-study based empirical analysis. Journal of Engineering and Technology Management, 8(3-4), 287-312.

Gupta, U. G., \& Clarke, R. E. (1996). Theory and applications of the delphi technique: A bibliography (1975-1994). Technological Forecasting and Social Change, 53(2), 185-211.

Jadhav, J. R., Mantha, S. S., \& Rane, S. B. (2014). Development of framework for sustainable lean implementation: An ISM approach. Journal of Industrial Engineering International, 10(3), 1-27.

Jia, P., Diabat, A., \& Mathiyazhagan , K. (2014). Analyzing the SSCM practices in the mining and mineral industry by ISM approach. Resources Policy (In Press).

Kannan, G., Pokharel, S., \& Kumar, P. S. (2009). A hybrid approach using ISM and fuzzy TOPSIS for the selection of reverse logistics provider. Resources, Conservation and Recycling, 54(1), 28-36.

Khalil, T. (2000). Management of technology: The key to competitiveness and wealth creation. New York: McGraw Hill.

Lai, W.-H. (2011). Willingness-to-engage in technology transfer in industry-university collaborations. Journal of Business Research, 64(11), 1218-1223.

Lai, W.-H., \& Tsai, C.-T. (2009). Fuzzy rule-based analysis of firm's technology transfer in Taiwan's machinery industry. Expert Systems with Applications, 36(10), 12012-12022. 
Lee, A. H., Wang, W.-M., \& Lin, T.-Y. (2010). An evaluation framework for technology transfer of new equipment in high technology industry. Technological Forecasting and Social Change, 77(1), 135-150.

Lee, S., Kim, W., Kim, Y. M., \& Oh, K. J. (2012). Using AHP to determine intangible priority factors for technology transfer adoption. Expert Systems with Applications, 39(7), 6388-6395.

Leitner, K.-H. (2005). Managing and reporting intangible assets in research technology organisations. $R \& D$ Management, 35(2), 125-136.

Lin, C., Tan, B., \& Chang, S. (2002). The critical factors for technology absorptive capacity. Industrial Management \& Data Systems, 102(6), 300-308.

Loo, R. (2002). The Delphi method: A powerful tool for strategic management. Policing: An International Journal of Police Strategies \& Management, 25(4), 762-769.

Morrissey, M. T., \& Sergio, A. (2005). Rethinking technology transfer. Journal of Food Engineering, 67(1-2), 135-145.

Nath, P., \& Mrinalini, N. (2000). Benchmarking the best practices of non-corporate R\&D organizations. Benchmarking: An International Journal, 7(2), 86-97.

Ounjian, M. L., \& Carne, E. (1987). A study of the factors which affect technology transfer in a multilocation multibusiness unit corporation. IEEE Transactions on Engineering Management, 34(3), 194-201.

Sharif, N., \& Baark, E. (2011). The transformation of research technology organisations (RTOs) in Asia and Europe. Science, Technology \& Society, 16(1), 1-10.

Singha, M. D., \& Kant, R. (2008). Knowledge management barriers: An interpretive structural modeling approach. International Journal of Management Science and Engineering Management, 3(2), 141-150.

Skulmoski, G., Hartman, F., \& Krahn, J. (2007). The Delphi method for graduate research. Journal of Information Technology Education: Research, 6(1), 1-21.

Smith, M. E., Lyles, M. A., \& Tsang, E. W. (2008). Inter-organizational knowledge transfer: Current themes and future prospects. Journal of Management Studies, 45(4), 677-690.

Stock, G. N., \& Tatikonda, M. V. (2000). A typology of project-level technology transfer processes. Journal of Operations Management, 18(6), 719-737.

Sung, T. K. (2009). Technology transfer in the IT industry: A Korean perspective. Technological Forecasting and Social Change, 76(5), 700-708.

Wahab, S. A., Rose, R. C., \& Osman, S. I. (2012). Defining the concepts of technology and technology transfer: A literature analysis. International Business Research, 5(1), 61-71.

Winebrake, J. J. (1992). A Study of technology-transfer mechanisms for federally funded R\&D. The Journal of Technology Transfer, 17(4), 54-61. 